\title{
Myeloid-Derived Suppressor Cells Hinder the Anti-Cancer Activity of Immune Checkpoint Inhibitors
}

\author{
Rebekka Weber ${ }^{1,2,3}$, Viktor Fleming ${ }^{1,2,3}$, Xiaoying Hu ${ }^{1,2}$, Vasyl Nagibin ${ }^{1,2}$, Christopher Groth ${ }^{1,2}$, \\ Peter Altevogt ${ }^{1,2}$, Jochen Utikal ${ }^{1,2}$ and Viktor Umansky ${ }^{1,2 *}$
}

'Skin Cancer Unit, German Cancer Research Center (DKFZ), Heidelberg, Germany, ${ }^{2}$ Department of Dermatology, Venereology and Allergology, University Medical Center Mannheim, Ruprecht-Karl University of Heidelberg, Mannheim, Germany, ${ }^{3}$ Faculty of Biosciences, Ruprecht-Karl University of Heidelberg, Heidelberg, Germany

\section{OPEN ACCESS}

Edited by: Amedeo Amedei,

Università degli Studi di Firenze, Italy

Reviewed by:

Rodabe N. Amaria,

University of Texas MD Anderson

Cancer Center, United States

Ekaterina Jordanova,

Center for Gynecologic Oncology

Amsterdam, Netherlands

*Correspondence:

Viktor Umansky

v.umansky@dkfz.de

Specialty section:

This article was submitted

to Cancer Immunity

and Immunotherapy,

a section of the journal

Frontiers in Immunology

Received: 30 March 2018

Accepted: 25 May 2018

Published: 11 June 2018

Citation:

Weber R, Fleming V, Hu X, Nagibin V, Groth C, Altevogt P, Utikal $J$ and Umansky V (2018) Myeloid-Derived

Suppressor Cells Hinder the Anti-Cancer Activity of Immune Checkpoint Inhibitors.

Front. Immunol. 9:1310. doi: 10.3389/fimmu.2018.01310
Immune checkpoint inhibitors (ICI) used for cancer immunotherapy were shown to boost the existing anti-tumor immune response by preventing the inhibition of $T$ cells by tumor cells. Antibodies targeting two negative immune checkpoint pathways, namely cytotoxic T-lymphocyte-associated protein 4 (CTLA-4), programmed cell death protein 1 (PD-1), and programmed cell death-ligand 1 (PD-L1), have been approved first for patients with melanoma, squamous non-small cell lung cancer (NSCLC), and renal cell carcinoma. Clinical trials are ongoing to verify the efficiency of these antibodies for other cancer types and to evaluate strategies to block other checkpoint molecules. However, a number of patients do not respond to this treatment possibly due to profound immunosuppression, which is mediated partly by myeloid-derived suppressor cells (MDSC). This heterogeneous population of immature myeloid cells can strongly inhibit anti-tumor activities of $\mathrm{T}$ and NK cells and stimulate regulatory T cells (Treg), leading to tumor progression. Moreover, MDSC can contribute to patient resistance to immune checkpoint inhibition. Accumulating evidence demonstrates that the frequency and immunosuppressive function of MDSC in cancer patients can be used as a predictive marker for therapy response. This review focuses on the role of MDSC in immune checkpoint inhibition and provides an analysis of combination strategies for MDSC targeting together with $\mathrm{ICI}$ to improve their therapeutic efficiency in cancer patients.

Keywords: myeloid-derived suppressor cells, immunosuppression, cancer immunotherapy, immune checkpoint inhibition, combination therapy

\footnotetext{
Abbreviations: ATRA, all-trans retinoic acid; ARG-1, arginase-1; bFGF, basic fibroblast growth factor; CCR, C-C chemokine receptor; CCL, C-C motif chemokine ligand; CXCL, C-X-C motif chemokine ligand; CCRK, cell cycle-related kinase; CSF-1R, colony stimulating factor 1 receptor; CTLA-4, cytotoxic T-lymphocyte-associated protein 4; DAMP, damage-associated molecular pattern; DC, dendritic cells; GM-CSF, granulocyte-macrophage colony stimulating factor; ICI, immune checkpoint inhibitors; IDO, indoleamine 2,3-dioxygenase; iNOS, inducible nitric oxide synthase; IFN, interferon; IL, interleukin; JAK, Janus kinase; MMP, matrix metalloproteinases; MyD88, myeloid differentiation primary response 88, MDSC, myeloid-derived suppressor cells; NK, natural killer; NO, nitric oxide; NSCLC, non-small cell lung cancer; NF-kB, nuclear factor "kappa-lightchain-enhancer" of activated B-cells; NY-ESO-1, New York esophageal squamous cell carcinoma-1; PBMC, peripheral blood mononuclear cells; PI3K, phosphatidylinositol-4,5-bisphosphate 3-kinase; PDE5, phosphodiesterase-5; PD-1, programmed cell death protein 1, PD-L1, programmed cell death-ligand 1; ROS, reactive oxygen species; Treg, regulatory T cells; STAT, signal transducer and activator of transcription; TCR, T cell receptor; TLR, toll-like receptor; TGF, transforming growth factor; VEGF, vascular endothelial growth factor; VEGFR, VEGF receptor.
} 


\section{INTRODUCTION}

Cancer immunotherapy has become a promising approach to treat patients over the past decade (1). Furthermore, new types of cancer immunotherapy that are currently under investigation will impact the treatment of cancer patients in the future. Among immunotherapeutic approaches, immune checkpoint inhibition is very promising. However, other types of immunotherapies such as monoclonal antibodies against tumor-associated antigens, cancer vaccines, cell therapy, and unspecific boosting of the immune system with interleukins (IL), interferons (IFN), or toll-like receptor (TLR) ligands are also used and/or under investigation (2).

Immune checkpoint pathways are important to restrict excessive immune responses (3). However, under cancer conditions, tumor cells can exploit these mechanisms to impair or prevent the tumor-targeted immune response. Signals transmitted to T cells either via programmed cell death protein 1 (PD-1) or cytotoxic T-lymphocyte-associated protein 4 (CTLA-4) promote T cell anergy and thereby switch off the immune response. Therefore, blockers of these immune checkpoint molecules have been shown to restore an immune response against cancer and increase patient survival $(4,5)$.

Ipilimumab (monoclonal antibody against CTLA-4) is used for the therapy of cutaneous melanoma. Nivolumab and pembrolizumab (monoclonal antibodies against PD-1) are approved for the therapy of cutaneous melanoma, non-small cell lung cancer (NSCLC), kidney cancer, bladder cancer, head and neck cancers, and Hodgkin lymphoma. Atezolizumab [monoclonal antibody against programmed cell death-ligand 1 (PD-L1)] is approved for the treatment of NSCLC and bladder cancer and avelumab (monoclonal antibody against PD-L1) is approved for gastric cancer and Merkel cell carcinoma therapy. Despite the fact that these immune checkpoint inhibitors (ICI) have proved to be effective, therapeutic resistance occurs in the majority of patients, leading to tumor progression $(5,6)$. This occurs due to the immunosuppressive tumor microenvironment represented by several immunosuppressive factors and cells, including myeloid-derived suppressor cells (MDSC) (7-10). Importantly, the efficacy of cancer immunotherapy has been reported to be negatively correlated with an increased MDSC frequency and function (11-15).

Myeloid-derived suppressor cells play a leading role in immunosuppression in various cancer types. Accumulating evidences in recent years have even highlighted them as a major driver of an immunosuppressive tumor microenvironment $(7-10,16)$. Therefore, MDSC could be a promising target in cancer immunotherapy especially in combination with ICI. In this review, we discuss the phenotypic and functional properties of MDSC as well as strategies for their therapeutic targeting. In particular, we address the role of MDSC in immune checkpoint inhibition and provide an analysis of the combination strategies for MDSC targeting together with ICI to improve their therapeutic efficiency in cancer patients.

\section{PHENOTYPIC AND FUNCTIONAL PROPERTIES OF MDSC}

Myeloid-derived suppressor cells represent a heterogeneous population of myeloid cells that fail to differentiate into granulocytes, macrophages, or dendritic cells (DC) but expand during cancer and chronic infection (17-20). They can strongly suppress the activity of T cells, natural killer (NK) cells, and some myeloid cells such as DC (8). MDSC have been identified to expand and play an important role in various cancer types, for example, in patients with melanoma (15, 21-24), multiple myeloma (25), hepatocellular carcinoma (26), NSCLC (27), renal cell carcinoma (28), breast cancer (29), prostate cancer (30), and colorectal cancer (31).

\section{MDSC Phenotype}

In mice, MDSC were characterized by the expression of CD11b and Gr1. However, the use of these markers is no longer sufficient, since MDSC can be divided into two subpopulations in mice: CD11 b ${ }^{+}$Ly6G ${ }^{-}$Ly6C ${ }^{\text {high }}$ monocyticMDSC (M-MDSC) and CD11b ${ }^{+}$ Ly6 $\mathrm{G}^{\text {high }}$ Ly6 ${ }^{\text {low }}$ polymorphonuclear MDSC (PMN-MDSC) (32). Human M-MDSC are defined as $\mathrm{Lin}^{-} \mathrm{CD} 11 \mathrm{~b}^{+} \mathrm{CD} 14^{+} \mathrm{CD} 15^{-} \mathrm{HLA}-$ $\mathrm{DR}^{- \text {llow }}$ and PMN-MDSC as $\mathrm{Lin}^{-} \mathrm{CD} 11 \mathrm{~b}^{+} \mathrm{CD} 14^{-} \mathrm{CD} 15^{+} \mathrm{HLA}-\mathrm{DR}^{-}$ or $\mathrm{Lin}^{-} \mathrm{CD} 11 \mathrm{~b}^{+} \mathrm{CD} 14^{-} \mathrm{CD}^{-} 6 \mathrm{~b}^{+}(32,33)$. One-third subtype of human MDSC, containing more immature HLA-DR ${ }^{-} \mathrm{CD} 33^{+} \mathrm{CD}$ $15^{-} \mathrm{CD} 14^{-} \mathrm{MDSC}$, has been recently proposed and was termed early stage MDSC (eMDSC) (32).

\section{MDSC Expansion and Activation}

Myeloid-derived suppressor cells are absent in the circulation under homeostatic conditions, but they can be accumulated under pathological conditions like chronic inflammation and cancer (34-39). The expansion and activation of MDSC are controlled by a complex network of soluble factors like IL-6, granulocyte-macrophage colony stimulating factor (GM-CSF), IL-10, M-CSF, G-CSF, and vascular endothelial growth factor (VEGF) as well as TLR ligands $(8,17,20,32,40)$. The process of MDSC generation is supposed to be divided into two phases that include MDSC accumulation and activation (8, 18-20, 40). MDSC enrichment is mediated by the blockade of the terminal differentiation of immature myeloid cells into granulocytes, macrophages, and DC due to an alteration of the growth factor composition, where G-CSF, GM-CSF, and VEGF play a major role. MDSC activation is mediated by the long-term secretion of cytokines like IL- 6 , IL-10, IL-1 $\beta$, and IFN- $\gamma$, as well as TLR ligands, such as damage-associated molecular pattern molecules produced under chronic inflammation $(8,18-20,40)$.

The production of immunosuppressive factors is driven via the Janus kinase (JAK)/signal transducer and activator of transcription (STAT) and myeloid differentiation primary response 88/ nuclear factor "kappa-light-chain-enhancer" of activated B-cells signal transduction cascades in $\operatorname{MDSC}(17,40)$.

\section{MDSC Function}

Activated MDSC produce elevated levels of nitric oxide (NO) via inducible nitric oxide synthase (iNOS) and upregulate the expression of arginase-1 (ARG-1), both leading to cell cycle arrest in $\mathrm{T}$ cells via depletion of the amino acid $\mathrm{L}$-arginine from the tumor microenvironment $(41,42)$ and to $\mathrm{T}$ cell anergy induced by the downregulation of $\mathrm{T}$ cell receptor (TCR) $\zeta$-chain expression $(16,43)$. Moreover, NO and reactive oxygen species produced by MDSC can induce $\mathrm{T}$ cell apoptosis or TCR nitrosylation $(44,45)$. In addition, activated MDSC express high levels of PD-L1 
$(46,47)$ that interacts with PD-1 on T cells and causes their exhaustion (48). MDSC also express elevated levels of indoleamine 2,3-dioxygenase (IDO), an enzyme degrading L-tryptophan into $\mathrm{N}$-formylkynurenine (49). The starvation from the amino acid L-tryptophan can lead to T cell arrest and anergy (50). Furthermore, it has been shown to drive the differentiation of $\mathrm{CD}^{+} \mathrm{T}$ cells into immunosuppressive regulatory $\mathrm{T}$ cells (Tregs) (51). MDSC can also induce Treg expansion and reduction of the anti-tumor activity of effector T cells via the expression of CD40 (52) and the secretion of transforming growth factor- $\beta$ and IL-10 (53-55). Furthermore, MDSC impair the Fc receptor-mediated functions of NK cells by the production of NO (56).

In addition to their immunosuppressive properties, MDSC can have other tumor promoting effects. In particular, they stimulate tumor angiogenesis by secreting VEGF and basic fibroblast growth factor $(57,58)$. By secreting matrix metalloproteinases (MMP), especially MMP9, they mediate a lower integrity of the extracellular matrix and the basal membrane, which enables tumor cells to enter the blood stream and form metastasis $(59,60)$. MDSC were also shown to play an important role in the formation of the pre-metastatic niche, a microenvironment in a secondary organ, facilitating metastasis (61).

\section{MDSC AS A PREDICTIVE MARKER IN IMMUNE CHECKPOINT INHIBITION FOR CANCER THERAPY}

Myeloid-derived suppressor cells have been reported to be an important prognostic marker for ICI treatment. Interestingly, MDSC levels could be used to predict therapy response or resistance to ipilimumab treatment in metastatic melanoma patients (62). Clinical responders to ipilimumab therapy showed a significantly lower percentage of $\mathrm{Lin}^{-} \mathrm{CD} 14^{+} \mathrm{HLA}-\mathrm{DR}^{-} \mathrm{M}-\mathrm{MDSC}$ in the peripheral blood as compared to non-responders. This finding suggests the use of circulating M-MDSC frequency as a marker of response, since low frequencies identified patients who could benefit from ipilimumab treatment (62). These data are in agreement with the results from another study, showing that a higher M-MDSC frequency prevented ipilimumabinduced activation and expansion of tumor-specific $\mathrm{T}$ cells resulting in the lower clinical response (23). It was shown by three more studies that a lower frequency of circulating MDSC at baseline can be used as a predictive marker for ipilimumab treatment of malignant melanoma patients (14, 15, 63). Moreover, in prostate cancer patients treated with a cancer vaccine in combination with ipilimumab, a lower frequency of circulating MDSC was found to correlate with an increased overall survival of patients (64).

\section{STRATEGIES FOR MDSC THERAPEUTIC TARGETING TO OVERCOME RESISTANCE TO ICI}

Due to important role of MDSC in tumor-induced immunosuppression, these cells could be a promising target for a combination therapy with ICI. There are three different approaches to target MDSC, namely the inhibition of (i) MDSC accumulation; (ii) MDSC trafficking; and (iii) MDSC-mediated immunosuppression.

\section{Reduction of MDSC Frequency}

To reduce MDSC frequency, the process of myelopoiesis has to be normalized and MDSC accumulation has to be blocked. Some chemotherapeutics were shown to affect MDSC in tumor-bearing hosts. Using the RET transgenic mouse model of malignant melanoma, it was demonstrated that ultra-low non-cytotoxic doses of paclitaxel induced a reduction of MDSC numbers and immunosuppressive activity, resulting in an increased survival of melanoma-bearing mice (65). Furthermore, the treatment of pancreatic cancer patients with gemcitabine led to a reduced number of PMN-MDSC (66). In colorectal cancer patients, the treatment with FOLFOX (folinic acid, 5-fluorouracil, and oxaliplatin) resulted in a reduced immunosuppression and a better clinical outcome that could be attributed to a decrease in MDSC frequency and restored anti-tumor immunity (67).

It has been described that the blockade of retinoic acid signal transduction by all-trans retinoic acid (ATRA) led to the differentiation of MDSC into macrophages and DC in murine and human cell samples (68). ATRA has been applied in two clinical trials, including patients with metastatic renal cell carcinoma and late stage small cell lung cancer, leading to a reduction of MDSC frequencies and an improvement of the patient survival $(69,70)$.

\section{Blockade of MDSC Recruitment}

To exhibit their immunosuppressive phenotype, MDSC have to be recruited to the tumor site. This process is mediated mainly by chemokines secreted in the tumor microenvironment and chemokine receptors expressed on $\operatorname{MDSC}(71,72)$. The role of $\mathrm{C}-\mathrm{C}$ motif chemokine ligand (CCL) 2 and its receptors $\mathrm{C}-\mathrm{C}$ chemokine receptor (CCR) 2 and 4 in the recruitment of M-MDSC has been well-documented $(71,73)$. Moreover, it was recently found that CCR5 is expressed on MDSC in RET transgenic melanomabearing mice and melanoma patients, playing an important role in their recruitment to the tumor microenvironment via the CCR5 ligands (CCL3, CCL4, and CCL5) (74, 75). Interestingly, $\mathrm{CCR}^{+}$MDSC were reported to display higher immunosuppressive potential than their CCR5 $5^{-}$counterpart both in mice and patients (74). Moreover, the blockade of the interaction of CCR5 with its ligands by a mCCR5-Ig fusion protein significantly improved the survival of melanoma-bearing animals (74). In addition, in a prostate cancer mouse model, the recruitment of $\mathrm{CD} 11 \mathrm{~b}^{+} \mathrm{Gr} 1^{+}$MDSC could be blocked by a CXC chemokine receptor 2 antagonist, thereby potentiating the therapeutic effect of the chemotherapeutic drug docetaxel (76).

\section{Inhibition of MDSC-Mediated Immunosuppression}

Phosphodiesterase-5 inhibitors (sildenafil, tadalafil, and vardenafil) are currently in clinical use for non-tumor conditions (77). However, sildenafil was already shown in several transplantable tumor mouse models to downregulate ARG-1 and iNOS expression in MDSC reducing thereby their immunosuppressive capacity and leading to an enhanced intratumoral $\mathrm{T}$ cell infiltration 
and activation, a reduction of tumor growth, and an improvement of the anti-tumor efficacy of adoptive T cell therapy (78). In the RET transgenic melanoma mouse model, sildenafil could also prolong mouse survival that was associated with reduced levels and activity of MDSC in the tumor microenvironment and, therefore, with a restored $\mathrm{CD} 8^{+} \mathrm{T}$ cell infiltration and function (79). Furthermore, in an inflammation-dependent murine colon cancer model, sildenafil prevented tumorigenesis by inhibiting tumor infiltration with MDSC (80).

In clinical trials, tadalafil was applied in patients with head and neck squamous cell carcinoma and metastatic melanoma (81-83). It improved clinical outcome and augmented the anti-tumor immune response of patients due to the reduction of peripheral and tumor-infiltrating MDSC, highlighting thereby its potential application in combined immunotherapy (81-83).

Another promising approach is targeting of STAT3, since it is a main regulator of MDSC immunosuppressive activity $(8,18-20$,
40, 84). Systemic administration of the STAT3 antisense oligonucleotide inhibitor AZD9150 was already tested in a phase I clinical trial in patients with lung cancer and lymphoma (85). It has been recently developed a strategy aiming to target STAT3 decoy oligonucleotides specifically to myeloid cells by coupling them to the TLR9 ligand CpG, which led to a reduced ARG-1 expression and to the restoration of $\mathrm{T}$ cell functions in patients with acute myeloid leukemia (86).

\section{COMBINATION OF ICI AND MDSC NEUTRALIZATION}

In recent years, the combination of MDSC targeting with ICI treatment has been applied in preclinical tumor models and cancer patients. Figure 1 illustrates the effect of combination of ICI and MDSC-targeted therapy to enable an anti-tumor immune response. Interestingly, it was shown that anti-PD-1

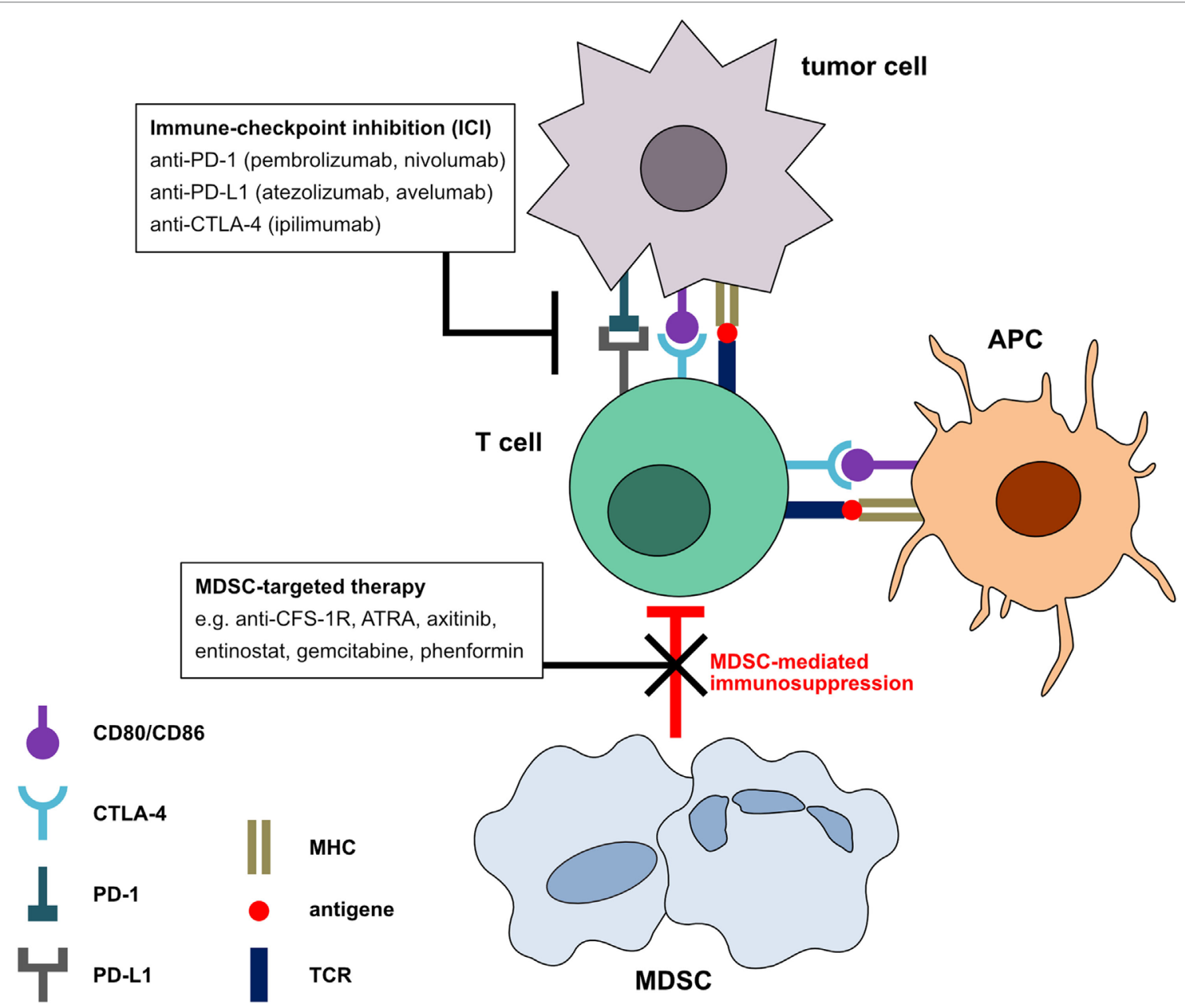

FIGURE 1 | Mechanism of immune checkpoint inhibitors (ICl) in combination with myeloid-derived suppressor cell (MDSC) neutralization. In the tumor microenvironment, tumor and antigen-presenting cells express the ligands for programmed cell death protein 1 and cytotoxic T-lymphocyte-associated protein 4 receptors on T cells. Signals transmitted via these receptors induce a T cell arrest and the termination of the anti-tumor immune response. Blockade of these negative checkpoint molecules can restore the anti-tumor activity of T cells. However, MDSC can induce T cell inhibition by mechanisms different from negative checkpoint molecules. The combination of MDSC inhibition with ICl could further increase T cell-mediated anti-tumor immune responses and the clinical outcome of cancer patients. 
antibodies themselves seem to have a direct effect on peripheral blood mononuclear cells (PBMC) from cancer patients. It was reported that anti-PD-1 antibodies stimulated in vitro PBMC proliferation induced by anti-CD3 antibodies and inhibited the induction of MDSC in the same experimental settings (87).

\section{ICI Plus Reduction of MDSC Frequency}

In two different tumor mouse models, the reduction of MDSC by a histone-deacetylase inhibitor, entinostat, in combination with antibodies against CTLA-4 and PD- 1 led to $80 \%$ tumor eradication although the application of these ICI alone failed to induce anti-tumor effects (88). In Lewis lung and renal cell carcinoma mouse models, MDSC blocking by entinostat in combination with PD-1 blockade resulted in a significantly increased survival in comparison to anti-PD-1 therapy alone (89). Furthermore, MDSC inhibition by phenformin, an antidiabetic drug from the biguanide class, was able to enhance the effect of PD-1 blockade reflected by an increased $\mathrm{CD}^{+} \mathrm{T}$ cell infiltration in the BRAF V600E/PTEN-null melanoma mouse model (90).

In a murine oral cancer model, anti-Ly6G antibodies were applied to deplete PMN-MDSC that resulted in the restoration of antigen-specific $\mathrm{T}$ cell responses but failed to improve mouse survival (91). However, the combination of anti-Ly6G and antiCTLA-4 antibodies induced a complete tumor rejection (91).

\section{ICI Combined With an Alteration of MDSC Function}

In a B16 melanoma mouse model expressing IDO, it has been shown that the blockade of colony stimulating factor 1 receptor (CSF-1R) by the kinase inhibitor PLX647 could inhibit tumorinfiltrating MDSC and enhance anti-tumor T cell responses (92). Moreover, this therapy sensitized the tumor for anti-PD-1 and anti-CTLA-4 antibodies, since the combination therapy led to an increased tumor regression and prolonged mouse survival as compared to the therapy with ICI alone (92). The same effect could be shown in CT26 colon and 4T1 breast cancer mouse models, where the combination of anti-CTLA-4 treatment with CSF-1/CSF-1R blockade enhanced the beneficial effect by reprogramming MDSC (93). Moreover, the expression of CSF-1 on tumor cells in melanoma and NSCLC patients correlated with the enrichment of MDSC that could be inhibited in vitro by the blockade of CSF-1/CSF-1R signaling (93). This observation was supported by another study, demonstrating that the blockade of M-CSF/CSF-1R interaction by BLZ945 could result in an improved efficacy of PD-1 blockade by inhibiting MDSC in mice with neuroblastoma (94).

The blockade of the VEGF receptor by axitinib in combination with anti-CTLA-4 antibodies increased survival of mice with subcutaneous melanoma and intracranial melanoma metastasis (95). This effect was due to an increased antigen-presenting capacity of DC and to a reduced suppressive capacity of M-MDSC, inducing the stimulation of $\mathrm{CD}^{+}$and $\mathrm{CD} 4^{+}$T cells (95).

Importantly, ICI treatment of head and neck cancer was reported to be noneffective due to the recruitment of MDSC (96). However, the treatment of mice bearing head and neck tumors with IPI-145, an inhibitor of phosphatidylinositol-4,5-bisphosphate 3-kinase $(\mathrm{PI} 3 \mathrm{~K}) \delta$ and $\mathrm{PI} 3 \mathrm{~K} \gamma$ isoforms, in combination with anti-PD-L1 antibodies resulted in the inhibition of MDSC activity associated with $\mathrm{CD}^{+} \mathrm{T}$ cell-dependent delay of tumor growth and with an improved survival (97).

It has been demonstrated that cell cycle-related kinase (CCRK) from human hepatocytes stimulated an expansion of

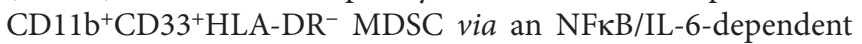
mechanism (98). Similarly, in CCRK transgenic mice, PMNMDSC frequency and activity were shown to be increased. Thus, upon inhibition of CCRK, PMN-MDSC numbers were decreased, an increased infiltration of IFN- $\gamma^{+} \mathrm{TNF}-\alpha^{+} \mathrm{CD} 8^{+}$ $\mathrm{T}$ cells was observed, and tumor progression was impaired (98). The beneficial effect was even stronger upon the combination with anti-PD-L1 antibodies (98).

\section{Ongoing Clinical Trials}

Some strategies modulating MDSC frequency and immunosuppressive function are already used in various clinical trials in combination with ICI (Table 1). Thus, a combined therapy with the anti-PD-L1 antibody atezolizumab and the histone-deacetylase inhibitor entinostat is currently under investigation in a phase I/II clinical trial in renal cell carcinoma patients. Furthermore, ATRA was applied in combination with ipilimumab in a phase II clinical trial in melanoma patients, inducing an improvement of clinical outcome associated with increased tumor antigen-specific $\mathrm{T}$ cell

TABLE 1 | Clinical trials combining myeloid-derived suppressor cell (MDSC) targeting with immune checkpoint inhibitors (ICI) in cancer patients.

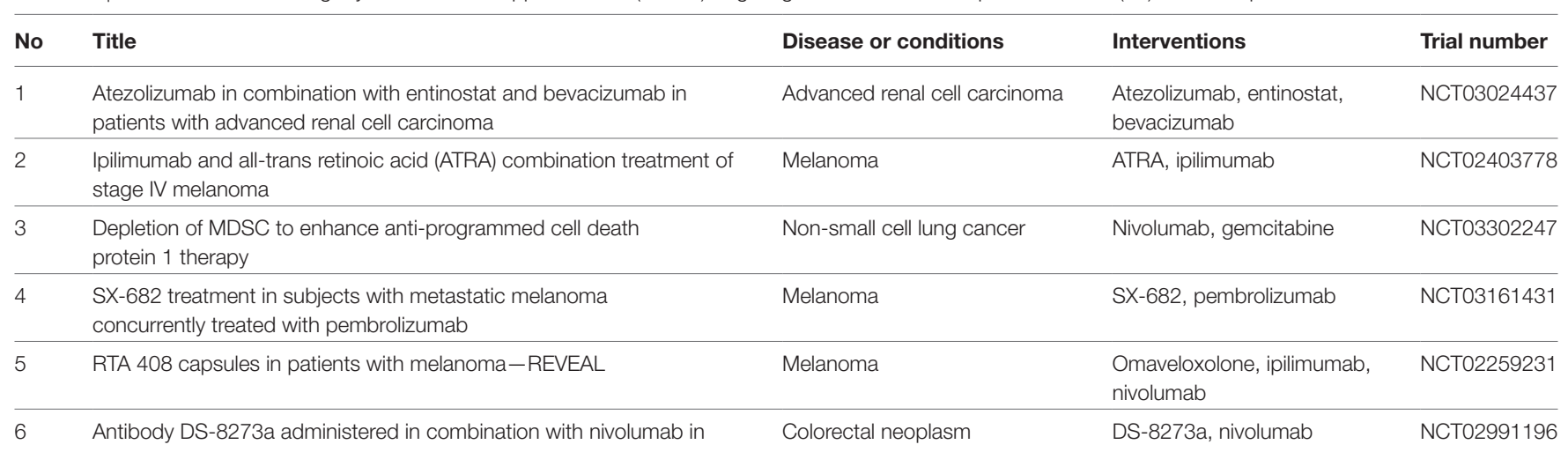

subjects with advanced colorectal cancer 
responses and decreased MDSC frequencies as compared to ipilimumab alone (99). Two other clinical trials in melanoma patients are utilizing the combination of ICI treatment with MDSC targeting by SX-682, a small-molecule dual-inhibitor of C-X-C motif chemokine ligand 1 and 2 , or by the antioxidative and anti-inflammatory drug omaveloxolone (RTA 408). Since it was shown that gemcitabine induced a reduction in MDSC numbers in pancreatic cancer patients (66), potentially increasing thereby the efficacy of nivolumab treatment, the combination of these drugs is applied in a phase II clinical trial in NSCLC patients. Furthermore, the tumor necrosis factor-related apoptosis inducing ligand (TRAIL) receptor 2 blocking antibodies DS-8273a, targeting MDSC in cancer patients (100), were applied in a phase I clinical trial in colorectal cancer patients in combination with nivolumab.

\section{CONCLUSION}

Immune checkpoint inhibitors for cancer therapy are approved for the treatment of cutaneous melanoma, NSCLC, kidney cancer, bladder cancer, head and neck cancers, Merkel cell carcinoma, gastric cancer, and Hodgkin lymphoma and could significantly improve the clinical outcome of cancer patients. However, the resistance to ICI after initial response or total lack of response is still a problem. Resistance can be mediated by MDSC, which makes these cells a promising target for combination therapy.

\section{REFERENCES}

1. Farkona S, Diamandis EP, Blasutig IM. Cancer immunotherapy: the beginning of the end of cancer? BMC Med (2016) 14:73. doi:10.1186/s12916016-0623-5

2. Emens LA, Ascierto PA, Darcy PK, Demaria S, Eggermont AMM, Redmond WL, et al. Cancer immunotherapy: opportunities and challenges in the rapidly evolving clinical landscape. Eur J Cancer (2017) 81:116-29. doi:10.1016/j. ejca.2017.01.035

3. Nirschl CJ, Drake CG. Molecular pathways: coexpression of immune checkpoint molecules: signaling pathways and implications for cancer immunotherapy. Clin Cancer Res (2013) 19:4917-24. doi:10.1158/1078-0432.CCR-12-1972

4. Wolchok JD, Saenger Y. The mechanism of anti-CTLA-4 activity and the negative regulation of T-cell activation. Oncologist (2008) 13(Suppl 4):2-9. doi:10.1634/theoncologist.13-S4-2

5. Hodi FS, O'Day SJ, McDermott DF, Weber RW, Sosman JA, Haanen JB, et al. Improved survival with ipilimumab in patients with metastatic melanoma. N Engl J Med (2010) 363:711-23. doi:10.1056/NEJMoa1003466

6. Robert C, Long GV, Brady B, Dutriaux C, Maio M, Mortier L, et al. Nivolumab in previously untreated melanoma without BRAF mutation. $N$ Engl J Med (2015) 372:320-30. doi:10.1056/NEJMoa1412082

7. Umansky V, Sevko A. Melanoma-induced immunosuppression and its neutralization. Semin Cancer Biol (2012) 22:319-26. doi:10.1016/j.semcancer. 2012.02.003

8. Kumar V, Patel S, Tcyganov E, Gabrilovich DI. The nature of myeloid-derived suppressor cells in the tumor microenvironment. Trends Immunol (2016) 37:208-20. doi:10.1016/j.it.2016.01.004

9. Ostrand-Rosenberg S, Fenselau C. Myeloid-derived suppressor cells: immune-suppressive cells that impair antitumor immunity and are sculpted by their environment. J Immunol (2018) 200:422-31. doi:10.4049/jimmunol. 1701019

10. Tcyganov E, Mastio J, Chen E, Gabrilovich DI. Plasticity of myeloid-derived suppressor cells in cancer. Curr Opin Immunol (2018) 51:76-82. doi:10.1016/j. coi.2018.03.009
In various preclinical tumor models, it has been reported that MDSC targeting potentiated the effect of ICI and led to a significantly increased survival and even to full tumor regression, which was not observed upon the treatment with ICI alone. However, only six early phase clinical trials are running to date to improve ICI outcome in cancer patients by reducing MDSC-mediated immunosuppression.

Therefore, more combinatorial trials are needed to use the strategies of MDSC neutralization to further improve the outcome of cancer immunotherapy by ICI.

\section{AUTHOR CONTRIBUTIONS}

RW: writing, review, and revision of the manuscript, preparation and revision of the figure and table. XH: preparation of the figure. VN: preparation of the table. VF, CG, PA, and JU: review and revision of the manuscript. VU: writing, review, and revision of the manuscript and revision of the table and figure.

\section{FUNDING}

This work was supported by grants from the German Research Council (RTG2099 to RW, JU, and VU) and the DKFZ-MOST Cooperation in Cancer Research (CA181 to CG and VU). This work was kindly backed by the COST Action BM1404 MyeEUNITER (www.mye-euniter.eu). COST is supported by the EU Framework Program Horizon 2020.

11. Hansen GL, Gaudernack G, Brunsvig PF, Cvancarova M, Kyte JA. Immunological factors influencing clinical outcome in lung cancer patients after telomerase peptide vaccination. Cancer Immunol Immunother (2015) 64:1609-21. doi:10.1007/s00262-015-1766-5

12. Limagne E, Euvrard R, Thibaudin M, Rébé C, Derangère V, Chevriaux A, et al. Accumulation of MDSC and Th17 cells in patients with metastatic colorectal cancer predicts the efficacy of a FOLFOX-bevacizumab drug treatment regimen. Cancer Res (2016) 76:5241-52. doi:10.1158/0008-5472. CAN-15-3164

13. Chesney JA, Mitchell RA, Yaddanapudi K. Myeloid-derived suppressor cells-a new therapeutic target to overcome resistance to cancer immunotherapy. J Leukoc Biol (2017) 102:727-40. doi:10.1189/jlb.5VMR1116-458RRR

14. Gebhardt C, Sevko A, Jiang H, Lichtenberger R, Reith M, Tarnanidis K, et al. Myeloid cells and related chronic inflammatory factors as novel predictive markers in melanoma treatment with ipilimumab. Clin Cancer Res (2015) 21:5453-9. doi:10.1158/1078-0432.CCR-15-0676

15. Martens A, Wistuba-Hamprecht K, Geukes Foppen M, Yuan J, Postow MA, Wong $\mathrm{P}$, et al. Baseline peripheral blood biomarkers associated with clinical outcome of advanced melanoma patients treated with ipilimumab. Clin Cancer Res (2016) 22:2908-18. doi:10.1158/1078-0432.CCR-15-2412

16. Parker KH, Beury DW, Ostrand-Rosenberg S. Myeloid-derived suppressor cells: critical cells driving immune suppression in the tumor microenvironment. Adv Cancer Res (2015) 128:95-139. doi:10.1016/bs.acr.2015.04.002

17. Gabrilovich DI, Nagaraj S. Myeloid-derived suppressor cells as regulators of the immune system. Nat Rev Immunol (2009) 9:162-74. doi:10.1038/ nri2506

18. Gabrilovich DI, Ostrand-Rosenberg S, Bronte V. Coordinated regulation of myeloid cells by tumours. Nat Rev Immunol (2012) 12:253-68. doi:10.1038/ nri3175

19. Ostrand-Rosenberg S. Myeloid-derived suppressor cells: more mechanisms for inhibiting antitumor immunity. Cancer Immunol Immunother (2010) 59:1593-600. doi:10.1007/s00262-010-0855-8

20. Veglia F, Perego M, Gabrilovich D. Myeloid-derived suppressor cells coming of age. Nat Immunol (2018) 19:108-19. doi:10.1038/s41590-017-0022-X 
21. Poschke I, Mougiakakos D, Hansson J, Masucci GV, Kiessling R. Immature immunosuppressive CD14+HLA-DR-/low cells in melanoma patients are Stat3hi and overexpress CD80, CD83, and DC-sign. Cancer Res (2010) 70:4335-45. doi:10.1158/0008-5472.CAN-09-3767

22. Jordan KR, Amaria RN, Ramirez O, Callihan EB, Gao D, Borakove M, et al. Myeloid-derived suppressor cells are associated with disease progression and decreased overall survival in advanced-stage melanoma patients. Cancer Immunol Immunother (2013) 62:1711-22. doi:10.1007/ s00262-013-1475-x

23. Weide B, Martens A, Zelba H, Stutz C, Derhovanessian E, Di Giacomo AM, et al. Myeloid-derived suppressor cells predict survival of patients with advanced melanoma: comparison with regulatory T cells and NY-ESO-1- or melan-A-specific T cells. Clin Cancer Res (2014) 20:1601-9. doi:10.1158/10780432.CCR-13-2508

24. Jiang H, Gebhardt C, Umansky L, Beckhove P, Schulze TJ, Utikal J, et al. Elevated chronic inflammatory factors and myeloid-derived suppressor cells indicate poor prognosis in advanced melanoma patients. Int J Cancer (2015) 136:2352-60. doi:10.1002/ijc.29297

25. Brimnes MK, Vangsted AJ, Knudsen LM, Gimsing P, Gang AO, Johnsen HE, et al. Increased level of both CD4+FOXP3+ regulatory $\mathrm{T}$ cells and CD14+HLA-DR-/low myeloid-derived suppressor cells and decreased level of dendritic cells in patients with multiple myeloma. Scand J Immunol (2010) 72:540-7. doi:10.1111/j.1365-3083.2010.02463.x

26. Hoechst B, Ormandy LA, Ballmaier M, Lehner F, Krüger C, Manns MP, et al. New population of myeloid-derived suppressor cells in hepatocellular carcinoma patients induces CD4+CD25+Foxp3+ T cells. Gastroenterology (2008) 135:234-43. doi:10.1053/j.gastro.2008.03.020

27. Liu C-Y, Wang Y-M, Wang C-L, Feng P-H, Ko H-W, Liu Y-H, et al. Population alterations of L-arginase- and inducible nitric oxide synthase-expressed CD11b+/CD14-/CD15+/CD33+ myeloid-derived suppressor cells and CD8+ T lymphocytes in patients with advanced-stage non-small cell lung cancer. JCancer Res Clin Oncol (2010) 136:35-45. doi:10.1007/s00432009-0634-0

28. van Cruijsen $H$, van der Veldt AAM, Vroling L, Oosterhoff D, Broxterman HJ, Scheper RJ, et al. Sunitinib-induced myeloid lineage redistribution in renal cell cancer patients: $\mathrm{CD} 1 \mathrm{c}+$ dendritic cell frequency predicts progression-free survival. Clin Cancer Res (2008) 14:5884-92. doi:10.1158/10780432.CCR-08-0656

29. Danilin S, Merkel AR, Johnson JR, Johnson RW, Edwards JR, Sterling JA. Myeloid-derived suppressor cells expand during breast cancer progression and promote tumor-induced bone destruction. Oncoimmunology (2012) 1:1484-94. doi:10.4161/onci.21990

30. Vuk-Pavlović S, Bulur PA, Lin Y, Qin R, Szumlanski CL, Zhao X, et al. Immunosuppressive CD14 + HLA-DR low/- monocytes in prostate cancer. Prostate (2010) 70:443-55. doi:10.1002/pros.21078

31. Chun E, Lavoie S, Michaud M, Gallini CA, Kim J, Soucy G, et al. CCL2 promotes colorectal carcinogenesis by enhancing polymorphonuclear myeloid-derived suppressor cell population and function. Cell Rep (2015) 12:244-57. doi:10.1016/j.celrep.2015.06.024

32. Bronte V, Brandau S, Chen S-H, Colombo MP, Frey AB, Greten TF, et al. Recommendations for myeloid-derived suppressor cell nomenclature and characterization standards. Nat Commun (2016) 7:12150. doi:10.1038/ ncomms 12150

33. Solito S, Marigo I, Pinton L, Damuzzo V, Mandruzzato S, Bronte V. Myeloidderived suppressor cell heterogeneity in human cancers. Ann N Y Acad Sci (2014) 1319:47-65. doi:10.1111/nyas.12469

34. Zhao F, Obermann S, von Wasielewski R, Haile L, Manns MP, Korangy F, et al. Increase in frequency of myeloid-derived suppressor cells in mice with spontaneous pancreatic carcinoma. Immunology (2009) 128:141-9. doi:10.1111/j.1365-2567.2009.03105.x

35. Gabitass RF, Annels NE, Stocken DD, Pandha HA, Middleton GW. Elevated myeloid-derived suppressor cells in pancreatic, esophageal and gastric cancer are an independent prognostic factor and are associated with significant elevation of the Th2 cytokine interleukin-13. Cancer Immunol Immunother (2011) 60:1419. doi:10.1007/s00262-011-1028-0

36. Ostrand-Rosenberg S, Sinha P. Myeloid-derived suppressor cells: linking inflammation and cancer. J Immunol (2009) 182:4499-506. doi:10.4049/ jimmunol.0802740
37. Ostrand-Rosenberg S. Myeloid derived-suppressor cells: their role in cancer and obesity. Curr Opin Immunol (2018) 51:68-75. doi:10.1016/j.coi. 2018.03.007

38. Umansky V, Sevko A. Overcoming immunosuppression in the melanoma microenvironment induced by chronic inflammation. Cancer Immunol Immunother (2012) 61:275-82. doi:10.1007/s00262-011-1164-6

39. Meirow Y, Kanterman J, Baniyash M. Paving the road to tumor development and spreading: myeloid-derived suppressor cells are ruling the fate. Front Immunol (2015) 6:523. doi:10.3389/fimmu.2015.00523

40. Condamine T, Gabrilovich DI. Molecular mechanisms regulating myeloidderived suppressor cell differentiation and function. Trends Immunol (2011) 32:19-25. doi:10.1016/j.it.2010.10.002

41. Rodriguez PC, Quiceno DG, Zabaleta J, Ortiz B, Zea AH, Piazuelo MB, et al. Arginase I production in the tumor microenvironment by mature myeloid cells inhibits T-cell receptor expression and antigen-specific T-cell responses. Cancer Res (2004) 64:5839-49. doi:10.1158/0008-5472. CAN-04-0465

42. Rodriguez PC, Quiceno DG, Ochoa AC. L-arginine availability regulates T-lymphocyte cell-cycle progression. Blood (2007) 109:1568-73. doi:10.1182/ blood-2006-06-031856

43. Baniyash MTCR. $\zeta$-chain downregulation: curtailing an excessive inflammatory immune response. Nat Rev Immunol (2004) 4:675-87. doi:10.1038/ nril 434

44. Nagaraj S, Gupta K, Pisarev V, Kinarsky L, Sherman S, Kang L, et al. Altered recognition of antigen is a mechanism of $\mathrm{CD} 8+\mathrm{T}$ cell tolerance in cancer. Nat Med (2007) 13:828-35. doi:10.1038/nm1609

45. Bogdan C. Nitric oxide and the immune response. Nat Immunol (2001) 2:907-16. doi:10.1038/ni1001-907

46. Noman MZ, Desantis G, Janji B, Hasmim M, Karray S, Dessen P, et al. PD-L1 is a novel direct target of HIF-1 $\alpha$, and its blockade under hypoxia enhanced MDSC-mediated T cell activation. J Exp Med (2014) 211:781-90. doi:10.1084/jem.20131916

47. Ostrand-Rosenberg S, Horn LA, Haile ST. The programmed death-1 immune-suppressive pathway: barrier to antitumor immunity. J Immunol (2014) 193:3835-41. doi:10.4049/jimmunol.1401572

48. Dieterich LC, Ikenberg K, Cetintas T, Kapaklikaya K, Hutmacher C, Detmar M. Tumor-associated lymphatic vessels upregulate PDL1 to inhibit T-cell activation. Front Immunol (2017) 8:66. doi:10.3389/fimmu.2017.00066

49. Yu J, Du W, Yan F, Wang Y, Li H, Cao S, et al. Myeloid-derived suppressor cells suppress antitumor immune responses through IDO expression and correlate with lymph node metastasis in patients with breast cancer. J Immunol (2013) 190:3783-97. doi:10.4049/jimmunol.1201449

50. Platten M, Wick W, Van den Eynde BJ. Tryptophan catabolism in cancer: beyond IDO and tryptophan depletion. Cancer Res (2012) 72:5435-40. doi:10.1158/0008-5472.CAN-12-0569

51. Munn DH, Sharma MD, Baban B, Harding HP, Zhang Y, Ron D, et al. GCN2 kinase in $\mathrm{T}$ cells mediates proliferative arrest and anergy induction in response to indoleamine 2,3-dioxygenase. Immunity (2005) 22:633-42. doi:10.1016/j.immuni.2005.03.013

52. Pan P-Y, Ma G, Weber KJ, Ozao-Choy J, Wang G, Yin B, et al. Immune stimulatory receptor $\mathrm{CD} 40$ is required for T-cell suppression and $\mathrm{T}$ regulatory cell activation mediated by myeloid-derived suppressor cells in cancer. Cancer Res (2010) 70:99-108. doi:10.1158/0008-5472.CAN-09-1882

53. Pistoia V, Morandi F, Bianchi G, Pezzolo A, Prigione I, Raffaghello L. Immunosuppressive microenvironment in neuroblastoma. Front Oncol (2013) 3:167. doi:10.3389/fonc.2013.00167

54. Umemura N, Saio M, Suwa T, Kitoh Y, Bai J, Nonaka K, et al. Tumorinfiltrating myeloid-derived suppressor cells are pleiotropic-inflamed monocytes/macrophages that bear M1- and M2-type characteristics. J Leukoc Biol (2008) 83:1136-44. doi:10.1189/jlb.0907611

55. Sinha P, Clements VK, Bunt SK, Albelda SM, Ostrand-Rosenberg S. Crosstalk between myeloid-derived suppressor cells and macrophages subverts tumor immunity toward a Type 2 response. J Immunol (2007) 179:977-83. doi:10.4049/jimmunol.179.2.977

56. Stiff A, Trikha P, Mundy-Bosse B, McMichael E, Mace TA, Benner B, et al. Nitric oxide production by myeloid-derived suppressor cells plays a role in impairing Fc receptor-mediated natural killer cell function. Clin Cancer Res (2018) 24:1891-904. doi:10.1158/1078-0432.CCR-17-0691 
57. Shen $\mathrm{P}$, Wang A, He M, Wang Q, Zheng S. Increased circulating Lin(-/low) CD33(+) HLA-DR(-) myeloid-derived suppressor cells in hepatocellular carcinoma patients. Hepatol Res (2014) 44:639-50. doi:10.1111/ hepr.12167

58. Schmid MC, Varner JA. Myeloid cells in tumor inflammation. Vasc Cell (2012) 4:14. doi:10.1186/2045-824X-4-14

59. Baniyash M. Myeloid-derived suppressor cells as intruders and targets: clinical implications in cancer therapy. Cancer Immunol Immunother (2016) 65:857-67. doi:10.1007/s00262-016-1849-y

60. Jacob A, Prekeris R. The regulation of MMP targeting to invadopodia during cancer metastasis. Front Cell Dev Biol (2015) 3:4. doi:10.3389/ fcell.2015.00004

61. Sceneay J, Parker BS, Smyth MJ, Möller A. Hypoxia-driven immunosuppression contributes to the pre-metastatic niche. Oncoimmunology (2013) 2:e22355. doi:10.4161/onci.22355

62. Meyer C, Cagnon L, Costa-Nunes CM, Baumgaertner P, Montandon N, Leyvraz L, et al. Frequencies of circulating MDSC correlate with clinical outcome of melanoma patients treated with ipilimumab. Cancer Immunol Immunother (2014) 63:247-57. doi:10.1007/s00262-013-1508-5

63. Sade-Feldman M, Kanterman J, Klieger Y, Ish-Shalom E, Olga M, Saragovi A, et al. Clinical significance of circulating CD33+CD11b+HLA-DR- myeloid cells in patients with Stage IV melanoma treated with ipilimumab. Clin Cancer Res (2016) 22:5661-72. doi:10.1158/1078-0432.CCR-15-3104

64. Santegoets SJ, Stam AG, Lougheed SM, Gall H, Jooss K, Sacks N, et al. Myeloid derived suppressor and dendritic cell subsets are related to clinical outcome in prostate cancer patients treated with prostate GVAX and ipilimumab. J Immunother Cancer (2014) 2:31. doi:10.1186/s40425-014-0031-3

65. Sevko A, Michels T, Vrohlings M, Umansky L, Beckhove P, Kato M, et al. Antitumor effect of paclitaxel is mediated by inhibition of myeloid-derived suppressor cells and chronic inflammation in the spontaneous melanoma model. J Immunol (2013) 190:2464-71. doi:10.4049/jimmunol.1202781

66. Eriksson E, Wenthe J, Irenaeus S, Loskog A, Ullenhag G. Gemcitabine reduces MDSCs, tregs and TGF $\beta-1$ while restoring the teff/treg ratio in patients with pancreatic cancer. J Transl Med (2016) 14:282. doi:10.1186/ s12967-016-1037-z

67. Kanterman J, Sade-Feldman M, Biton M, Ish-Shalom E, Lasry A, Goldshtein A, et al. Adverse immunoregulatory effects of 5FU and CPT11 chemotherapy on myeloid-derived suppressor cells and colorectal cancer outcomes. Cancer Res (2014) 74:6022-35. doi:10.1158/0008-5472.CAN-14-0657

68. Nefedova Y, Fishman M, Sherman S, Wang X, Beg AA, Gabrilovich DI. Mechanism of all-trans retinoic acid effect on tumor-associated myeloidderived suppressor cells. Cancer Res (2007) 67:11021-8. doi:10.1158/00085472.CAN-07-2593

69. Mirza N, Fishman M, Fricke I, Dunn M, Neuger AM, Frost TJ, et al. Alltrans-retinoic acid improves differentiation of myeloid cells and immune response in cancer patients. Cancer Res (2006) 66:9299-307. doi:10.1158/00085472.CAN-06-1690

70. Iclozan C, Antonia S, Chiappori A, Chen D-T, Gabrilovich D. Therapeutic regulation of myeloid-derived suppressor cells and immune response to cancer vaccine in patients with extensive stage small cell lung cancer. Cancer Immunol Immunother (2013) 62:909-18. doi:10.1007/s00262013-1396-8

71. Lesokhin AM, Hohl TM, Kitano S, Cortez C, Hirschhorn-Cymerman D, Avogadri F, et al. Monocytic CCR2(+) myeloid-derived suppressor cells promote immune escape by limiting activated CD8 T-cell infiltration into the tumor microenvironment. Cancer Res (2012) 72:876-86. doi:10.1158/00085472.CAN-11-1792

72. Umansky V, Blattner C, Gebhardt C, Utikal J. CCR5 in recruitment and activation of myeloid-derived suppressor cells in melanoma. Cancer Immunol Immunother (2017) 66:1015-23. doi:10.1007/s00262-017-1988-9

73. Zhang J, Patel L, Pienta KJ. CC chemokine ligand 2 (CCL2) promotes prostate cancer tumorigenesis and metastasis. Cytokine Growth Factor Rev (2010) 21:41-8. doi:10.1016/j.cytogfr.2009.11.009

74. Blattner C, Fleming V, Weber R, Himmelhan B, Altevogt P, Gebhardt C, et al. CCR5 + myeloid-derived suppressor cells are enriched and activated in melanoma lesions. Cancer Res (2018) 78:157-67. doi:10.1158/0008-5472. CAN-17-0348

75. Hawila E, Razon H, Wildbaum G, Blattner C, Sapir Y, Shaked Y, et al. CCR5 directs the mobilization of $\mathrm{CD} 11 \mathrm{~b}+\mathrm{Gr} 1+\mathrm{Ly} 6$ clowpolymorphonuclear myeloid cells from the bone marrow to the blood to support tumor development. Cell Rep (2017) 21:2212-22. doi:10.1016/j.celrep.2017.10.104

76. Di Mitri D, Toso A, Chen JJ, Sarti M, Pinton S, Jost TR, et al. Tumourinfiltrating Gr-1+ myeloid cells antagonize senescence in cancer. Nature (2014) 515:134-7. doi:10.1038/nature13638

77. Giovannoni MP, Vergelli C, Graziano A, Dal Piaz V. PDE5 inhibitors and their applications. Curr Med Chem (2010) 17:2564-87. doi:10.2174/ 092986710791859360

78. Serafini P, Meckel K, Kelso M, Noonan K, Califano J, Koch W, et al. Phosphodiesterase-5 inhibition augments endogenous antitumor immunity by reducing myeloid-derived suppressor cell function. J Exp Med (2006) 203:2691-702. doi:10.1084/jem.20061104

79. Meyer C, Sevko A, Ramacher M, Bazhin AV, Falk CS, Osen W, et al. Chronic inflammation promotes myeloid-derived suppressor cell activation blocking antitumor immunity in transgenic mouse melanoma model. Proc Natl Acad Sci U S A (2011) 108:17111-6. doi:10.1073/pnas.1108121108

80. Lin S, Wang J, Wang L, Wen J, Guo Y, Qiao W, et al. Phosphodiesterase-5 inhibition suppresses colonic inflammation-induced tumorigenesis via blocking the recruitment of MDSC. Am J Cancer Res (2017) 7:41-52.

81. Califano JA, Khan Z, Noonan KA, Rudraraju L, Zhang Z, Wang H, et al. Tadalafil augments tumor specific immunity in patients with head and neck squamous cell carcinoma. Clin Cancer Res (2015) 21:30-8. doi:10.1158/10780432.CCR-14-1716

82. Weed DT, Vella JL, Reis IM, De la Fuente AC, Gomez C, Sargi Z, et al. Tadalafil reduces myeloid-derived suppressor cells and regulatory $\mathrm{T}$ cells and promotes tumor immunity in patients with head and neck squamous cell carcinoma. Clin Cancer Res (2015) 21:39-48. doi:10.1158/1078-0432. CCR-14-1711

83. Hassel JC, Jiang H, Bender C, Winkler J, Sevko A, Shevchenko I, et al. Tadalafil has biologic activity in human melanoma. Results of a pilot trial with tadalafil in patients with metastatic melanoma (TaMe). Oncoimmunology (2017) 6:e1326440. doi:10.1080/2162402X.2017.1326440

84. Vasquez-Dunddel D, Pan F, Zeng Q, Gorbounov M, Albesiano E, Fu J, et al. STAT3 regulates arginase-I in myeloid-derived suppressor cells from cancer patients. J Clin Invest (2013) 123:1580-9. doi:10.1172/JCI60083

85. Hong D, Kurzrock R, Kim Y, Woessner R, Younes A, Nemunaitis J, et al. AZD9150, a next-generation antisense oligonucleotide inhibitor of STAT3 with early evidence of clinical activity in lymphoma and lung cancer. Sci Transl Med (2015) 7:314ra185. doi:10.1126/scitranslmed.aac5272

86. Zhang Q, Hossain DMS, Duttagupta P, Moreira D, Zhao X, Won H, et al. Serum-resistant CpG-STAT3 decoy for targeting survival and immune checkpoint signaling in acute myeloid leukemia. Blood (2016) 127:1687-700. doi:10.1182/blood-2015-08-665604

87. Akiyama Y, Nonomura C, Kondou R, Miyata H, Ashizawa T, Maeda C, et al. Immunological effects of the anti-programmed death-1 antibody on human peripheral blood mononuclear cells. Int J Oncol (2016) 49:1099-107. doi:10.3892/ijo.2016.3586

88. Kim K, Skora AD, Li Z, Liu Q, Tam AJ, Blosser RL, et al. Eradication of metastatic mouse cancers resistant to immune checkpoint blockade by suppression of myeloid-derived cells. Proc Natl Acad Sci U S A (2014) 111:11774-9. doi:10.1073/pnas.1410626111

89. Orillion A, Hashimoto A, Damayanti N, Shen L, Adelaiye-Ogala R, Arisa S, et al. Entinostat neutralizes myeloid-derived suppressor cells and enhances the antitumor effect of PD-1 inhibition in murine models of lung and renal cell carcinoma. Clin Cancer Res (2017) 23:5187-201. doi:10.1158/1078-0432. CCR-17-0741

90. Kim SH, Li M, Trousil S, Zhang Y, Pasca di Magliano M, Swanson KD, et al. Phenformin inhibits myeloid-derived suppressor cells and enhances the anti-tumor activity of PD-1 blockade in melanoma. J Invest Dermatol (2017) 137(8):1740-8. doi:10.1016/j.jid.2017.03.033

91. Clavijo PE, Moore EC, Chen J, Davis RJ, Friedman J, Kim Y, et al. Resistance to CTLA-4 checkpoint inhibition reversed through selective elimination of granulocytic myeloid cells. Oncotarget (2017) 8:55804-20. doi:10.18632/ oncotarget. 18437

92. Holmgaard RB, Zamarin D, Lesokhin A, Merghoub T, Wolchok JD. Targeting myeloid-derived suppressor cells with colony stimulating factor-1 receptor blockade can reverse immune resistance to immunotherapy in indoleamine 2,3-dioxygenase-expressing tumors. EBioMedicine (2016) 6:50-8. doi:10.1016/j. ebiom.2016.02.024 
93. Holmgaard RB, Brachfeld A, Gasmi B, Jones DR, Mattar M, Doman T, et al. Timing of CSF-1/CSF-1R signaling blockade is critical to improving responses to CTLA-4 based immunotherapy. Oncoimmunology (2016) 5:e1151595. doi:10.1080/2162402X.2016.1151595

94. Mao Y, Eissler N, Blanc KL, Johnsen JI, Kogner P, Kiessling R. Targeting suppressive myeloid cells potentiates checkpoint inhibitors to control spontaneous neuroblastoma. Clin Cancer Res (2016) 22:3849-59. doi:10.1158/10780432.CCR-15-1912

95. Du Four S, Maenhout SK, Niclou SP, Thielemans K, Neyns B, Aerts JL. Combined VEGFR and CTLA-4 blockade increases the antigen-presenting function of intratumoral DCs and reduces the suppressive capacity of intratumoral MDSCs. Am J Cancer Res (2016) 6:2514-31.

96. Höchst B, Knolle PA. Checkpoint inhibition in head and neck cancer: immune therapeutic options, limitations, and beyond. ORL J Otorhinolaryngol Relat Spec (2017) 79:24-33. doi:10.1159/000455810

97. Davis RJ, Moore EC, Clavijo PE, Friedman J, Cash H, Chen Z, et al. AntiPD-L1 efficacy can be enhanced by inhibition of myeloid-derived suppressor cells with a selective inhibitor of PI3Kס/ $\gamma$. Cancer Res (2017) 77:2607-19. doi:10.1158/0008-5472.CAN-16-2534

98. Zhou J, Liu M, Sun H, Feng Y, Xu L, Chan AWH, et al. Hepatomaintrinsic CCRK inhibition diminishes myeloid-derived suppressor cell immunosuppression and enhances immune-checkpoint blockade efficacy. Gut (2017) 67(5):931-44. doi:10.1136/gutjnl-2017-314032

99. Tobin RP, Davis D, Jordan KR, McCarter MD. The clinical evidence for targeting human myeloid-derived suppressor cells in cancer patients. J Leukoc Biol (2017) 102:381-91. doi:10.1189/jlb.5VMR1016-449R

100. Dominguez GA, Condamine T, Mony S, Hashimoto A, Wang F, Liu Q, et al. Selective targeting of myeloid-derived suppressor cells in cancer patients using DS-8273a, an agonistic TRAIL-R2 antibody. Clin Cancer Res (2017) 23:2942-50. doi:10.1158/1078-0432.CCR-16-1784

Conflict of Interest Statement: The authors declare that the research was conducted in the absence of any commercial or financial relationships that could be construed as a potential conflict of interest.

Copyright (C) 2018 Weber, Fleming, Hu, Nagibin, Groth, Altevogt, Utikal and Umansky. This is an open-access article distributed under the terms of the Creative Commons Attribution License (CC BY). The use, distribution or reproduction in other forums is permitted, provided the original author(s) and the copyright owner are credited and that the original publication in this journal is cited, in accordance with accepted academic practice. No use, distribution or reproduction is permitted which does not comply with these terms. 